\title{
NON EQUILIBRIUM LUMPED PARAMETER MODEL FOR PULSATING HEAT PIPES: VALIDATION IN NORMAL AND HYPER-GRAVITY CONDITIONS
}

\author{
Miriam Manzoni ${ }^{1}$, Mauro Mameli ${ }^{2 *}$, Carlo de Falco ${ }^{3}$, Lucio Araneo ${ }^{4}$, Sauro Filippeschi ${ }^{2}$, and \\ Marco Marengo ${ }^{1,5}$ \\ ${ }^{1}$ Università degli Studi di Bergamo, Dept. of Eng. and Applied Science, Viale Marconi 5, 24044 Dalmine (BG), Italy \\ ${ }^{2}$ Università di Pisa, DESTEC, Largo Lazzarino 2, 56122 Pisa, Italy \\ ${ }^{3}$ Politecnico di Milano, MOX, Modeling and Scientific Computing, Dept. of Mathematics, Piazza Leonardo da Vinci 32, 20133 Milano, \\ Italy \\ ${ }^{4}$ Politecnico di Milano, Energy Dept., Via Lambruschini 4A, 20158 Milano, Italy \\ ${ }^{5}$ University of Brighton, School of Computing, Eng. and Mathematics, Lewes Road, BN2 4GJ, Brighton, UK
}

*Corresponding author: mcjmameli@gmail.com

\begin{abstract}
As relatively new and promising members of the wickless heat pipes family, the pulsating heat pipes, with their high effective thermal conductivity, construction simplicity, low weight, and potential high power loads may answer the present industry demand of high heat transfer capability, efficient thermal control, flexibility and low cost. Numerous are the attempts to simulate their complex thermal behaviour, but none of the existing models is validated for transient operative conditions and under various gravity levels. Thus, a novel lumped parameters model able to compute the steady state as well as the transient performance of PHPs has been developed. It consists of a two-phase separated flow model applicable to a confined operating regime (slug-plug flow). A complete set of balance differential equations accounts for thermal and fluid-dynamic phenomena. The main originalities of this tool lay in the suppression of the standard assumption of saturated vapor plugs as well as in the consequent embedding of heterogeneous and homogeneous phase changes. In addition, an experimental work has been carried out with a 16 turns copper capillary PHP filled with FC-72. Therefore, the model has been validated in several operative conditions and under various gravity levels by comparison with these experimental data both in normal and hyper-gravity conditions showing very good prediction capability.
\end{abstract}

\section{KEY WORDS}

Pulsating Heat Pipe, Numerical model, Transient mode, Hyper-gravity

\section{INTRODUCTION}

Heat transfer systems are somewhat ubiquitous: they can be found in electronic devices, energy management components, in transportation, cooling and in households in general. The demand for higher performances, efficient thermal control and low cost has pushed researchers to develop a new generation of two-phase flow systems, mainly based on the phase change of a working fluid. However, the development of reliable devices, calls for a thorough understanding of fundamental principles and their modelling. In the past decades, wickless two-phase passive systems were born to meet industrial requests: such technologies, like Pulsating Heat Pipes (PHPs), have, indeed, an extremely high potential in terms of simplicity and, consequently, low cost.

Patented by Akachi in the '90 [1-2], a PHP consists of a capillary loop with alternated heating and cooling zones evacuated and partially filled with a working fluid. Due to capillary forces, a train of vapour bubbles and liquid slugs is usually generated within the channel, although this is not the only flow pattern recognizable in an operating PHP. Indeed, in particular conditions, other possible fluidic paths characterized by separation of vapor and liquid phase can appear (e.g. annular, stratification) [3]. When heat is provided to the evaporator section, the temperature increases, liquid evaporates, vapor pressure raises and a chaotic motion (i.e. oscillation and circulation) is induced within the channel pushing the train of fluidic elements towards the condenser section. In this zone at relatively lower temperature, vapor pressure decreases, condensation occurs and heat is rejected to the external environment. 
The PHP thermal-hydraulic behaviour is complex and, up to now, not fully defined, since it involves intricate thermal and fluidic dynamics as well as homogeneous and heterogeneous evaporation/condensation effects at the interface between the coexisting vapour and liquid elements. In addition, there is an interplay between phase change phenomena, capillary forces and gravity which may help or damp the fluid motion. Experimental studies on PHPs operating under different acceleration loads [4-11] have underlined a strong relationship between these complex phenomena and the PHP thermal response.

In the last two decades, many numerical works focused on the prediction of the actual PHP performance, but only few of them are capable of complete thermal-hydraulic simulations and even less are partially validated against experimental data ([12-13]). In addition, none of the existing models is validated for transient operations or under various gravity levels, even if hyper-gravity conditions commonly arise in several applications, from automotive to aerospace.

Since slug flow is the primary flow pattern in PHPs, most of the existing efforts have focused on it. The first analytical models developed to describe the PHP functioning were very simplified with many unrealistic assumptions. Two kinds of approaches can be usually recognized: the continuum wave propagation approach (e.g. [14-15]) which assumes pressure oscillations as fundamental to induce vapor-liquid circulation; the mass-spring-dampers approach applied to describe the motion of the liquid slug and vapor plugs as a train of linearized elements (e.g. [16-17]).

Wong et al. [18] developed the first numerical model describing an adiabatic slug flow in a capillary channel with a set of first order non linear differential equations. In the following, the non linear differential analysis, comprising or not heat transfer, became the standard way to acquire more insightful of PHPs thermalhydraulic behaviour. Most of these codes were simplified lumped parameters, one dimensional models, which assume saturated conditions and usually neglect the presence of the liquid film located between the internal tube wall and vapor plugs, even if its presence influences the performance of the device, as pointed out by Nikolayev et al. [19-20]. In 2005 Holley and Faghri [21] developed one of the most comprehensive numerical model concerning a PHP system. The 1-D lumped parameter model of a water PHP assumed, a priori, slug flow and saturated conditions. The momentum equation was solved for the liquid slugs, while the energy equation was considered for both phases and for the external wall. The model was able to account for liquid elements coalescence and new vapor formation although phase changes are not directly accounted for. Later Mameli et al. [22-24] improved Holley and Faghri model introducing the effects of the tube bends on the liquid slugs dynamic and the calculation of the two-phase heat transfer coefficient for liquid and vapour sections as function of the heating regime. Furthermore, an extended library of possible working fluid was included.

Recently attempts to model PHPs making use of Artificial Neural Networks (ANN, e.g. [25-27]) as well as Computational Fluid Dynamics (CFD, e.g. [28-29]) appear in literature. However, since the ANN approach does not include any physical model, it needs to be trained with large set of experimental data to provide results that, at the end, cannot be generalized. On the other hand, the CFD approach might achieve high modeling potential in the near future; however, up to now, such models lack of a thorough experimental validation. In addition, the CFD approach has too large computational costs to effectively replace lumped parameters models, especially if numerical analyses do not only aim at providing an increased understanding of the complex PHPs behaviour, but also to investigate novel and breakthrough methods to enhance the device performances.

In this paper, following the route opened by Holley and Faghri [21] and Mameli et al. [22-24], a novel lumped parameters model able to compute both the steady state and the transient operation of PHPs is presented. It consists of a two-phase separated flow model applicable to a confined operating regime. A complete set of balance differential equations accounts for thermal and fluid-dynamic phenomena. The main originalities of this tool lay in the suppression of the standard assumption of saturated vapor plugs as well as in the consequent embedding of heterogeneous and homogeneous phase changes. In addition, a novel correlation for the estimation of the wall/vapor heat transfer coefficient has been introduced, in order to account for the influence of the liquid film on the conjugate heat transfer. The model is here validated in several operative conditions and under various gravity levels by comparison with experimental data achieved on a planar copper PHP partially filled with FC-72 tested both in normal and hyper-gravity (ESA-ESTEC LDC) conditions [8].

\section{NUMERICAL MODEL}

The proposed numerical tool is a lumped parameters one-dimensional model applicable to a confined operating regime (i.e. slug flow) for a PHP of constant diameter (Fig. 1). 
The main assumptions are:

1. The model is one-dimensional. Mass, momentum and heat transfer are calculated along the axial direction, which follows the PHP tube. Heat transfer in radial direction is lumped.

2. All the fluid thermo-physical properties, apart from vapor pressure and density, are calculated as function of the temperature only. Liquid is assumed incompressible. Wall thermal properties are kept constant.

3. The momentum equation for each liquid slug is lumped and friction between vapor plugs and wall elements is neglected.

4. Liquid menisci maintain hemi-spherical shape with zero contact angles at the wall.

5. Vapor is treated as real gas. Density is calculated by definition (mass over volume). Van der Waals equation is adopted to defined the vapor pressure as function of temperature and density except in case of phase changes.

6. Vapor may exist in saturated, sub-cooled and super-heated conditions.

7. Heterogeneous phase changes are isothermal and isobaric; phase changes through the interface are isobaric but non-isothermal. Phase changes are always followed by isothermal compressions or expansions of vapor elements in order to re-adjust the total volume.

8. The temperature jump through the interface is neglected.

9. The thin liquid film around each vapor plug is neglected. It is only used to define the real volume occupied by each fluidic element within the tube inner channel, considering it constant in space and time.
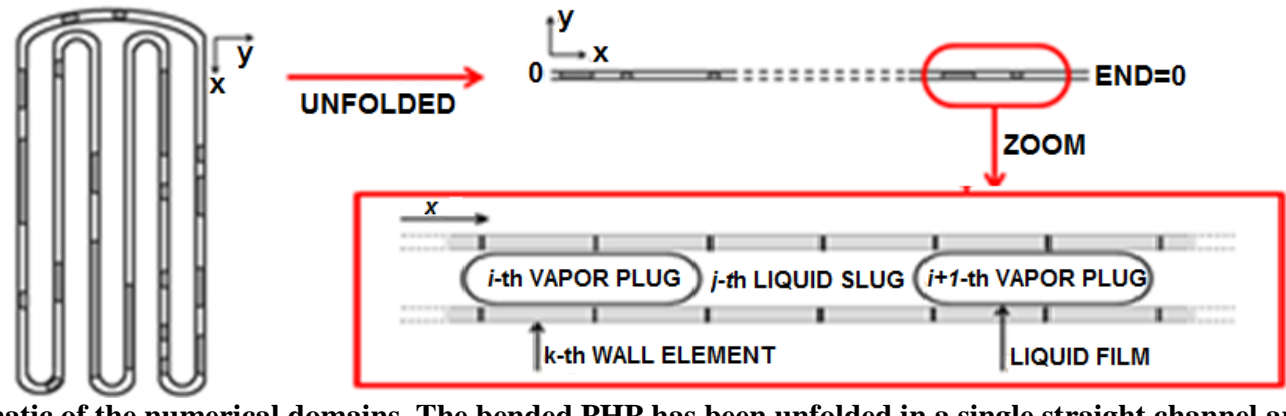

Fig. 1: Schematic of the numerical domains. The bended PHP has been unfolded in a single straight channel and subdivided into solid and fluidics regions. Liquid slugs sub-domains are not explicitly indicated. The wall is considered completely wettable.

\subsection{Solid Model}

The solid model describes the thermal behaviour of the PHP external wall. The capillary tube is sub-divided into $N_{w}$ smaller domains with constant length (Fig. 1) which are treated with an Eulerian approach, since the mass of the tube and the positions of the wall domains are not time dependent. A set of $N_{w}$ differential equations, describing the temperature evolution of each solid element, has been implemented and solved making use of the $1^{\text {st }}$ Adams-Bashforth integration scheme.

Accounting for assumption 2, the wall energy balance can be defined as:

$m_{w} c_{V, w} \frac{d T_{w}}{d t}=\left(\left.k_{w} A_{w} \frac{\partial T_{w}}{\partial x}\right|_{k} ^{k-1}-\left.k_{w} A_{w} \frac{\partial T_{w}}{\partial x}\right|_{k+1} ^{k}\right)-q_{w f, w} A_{w f}+q_{e x} A_{e x}$

where $m$ and $T$ are respectively the mass and the temperature of each domain, $k$ is the thermal conductivity of the wall material, $A_{w f}$ and $A_{e x}$ are relatively the internal tube surface in contact with the fluid and the external tube surface exposed to the environment; $A_{w}$ is the tube cross section area, as shown in Figure 2.

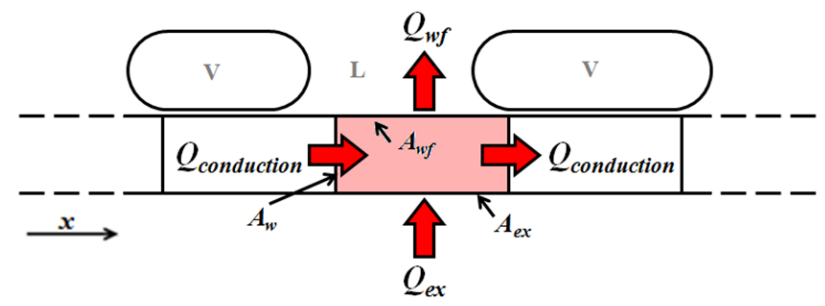

Fig. 2: Schematic of the wall energy balance for the $k$-th domain.

The first term on the right side of Equation 1 accounts for the heat conduction within the wall; the second term is the heat exchanged between the wall and the fluidic elements (section 2.3); the last term represents 
the heat exchanged between the wall and the external environment. Constant heat input power $Q_{e x}$ is supplied to the evaporator zone, forced convection is applied at the condenser, while no heat exchange occurs in the adiabatic region. Thus the applied boundary conditions are:

$q_{\text {ex }} \begin{cases}Q_{\text {ex }} / A_{\text {ex }} & \text { evaporator zone } \\ 0 & \text { adiabatic zone } \\ h_{\infty}\left(T_{\infty}-T_{w}\right) & \text { condenser zone }\end{cases}$

where $h_{\infty}$ is the external heat transfer coefficient and $T_{\infty}$ the environmental temperature (Tab. 2).

Radiation has been neglected since it is estimated less than $0.5 \%$ of the total dissipated heat in the worst case.

\subsection{Fluidic Model}

The fluidic model describes the thermo-dynamic behaviour of both liquid slugs and vapor bubbles; the thin liquid film around each vapor plug is assumed constant in space and time (Assumption 9). Since only slug flow is considered, when a Lagrangian approach is applied, liquid slugs and vapor plugs constitute physical control volumes (Fig. 1); thus, the numerical domains follow the fluidic elements in their chaotic/oscillating motion within the channel and each element is spatially traceable during the whole simulation time. In addition liquid slugs are subdivided into smaller sub-domains with equal length characterized by the same velocity but, eventually, different temperatures accounting for axial heat conduction within the liquid phase.

\subsubsection{Phase Changes}

Although the total mass of the system remains constant during the simulation time, the mass of each liquid and vapor element varies due to phase changes. Since vapor may exist both in saturated and not saturated conditions (Assumption 6), heterogeneous and homogenous phase changes through the interface must be taken into account.

Heterogeneous condensation/evaporation occurs when a vapor/liquid comes into contact with an object, at lower or higher temperature. This involves heat transfer to/from the solid wall. Otherwise, if vapor/liquid pressure is higher/lower than the saturation value at its actual temperature, homogeneous condensation/evaporation through the interface occurs in the fluidic bulk which represents the heat sink or source associated to this kind of transition. Thus proper conditions must be satisfied in both cases to allow phase changes:

Heterogeneous phase changes

$\left\{\begin{array}{llll}p_{v}>p_{\text {sat }} & \& & T_{w} \leq T_{v, \text { sat }}-\Delta T_{\text {cooling }} & \text { for condensation } \\ p_{l}<p_{\text {sat }} & \& & T_{w} \geq T_{l, \text { sat }}+\Delta T_{\text {super-heating }} & \text { for evaporation }\end{array}\right.$

Homogeneous phase changes through the interface

$\left\{P_{v}>P_{\text {sat }}\right.$ for condensation

$\left\{P_{v}<P_{\text {sat }}\right.$ for evaporation

where $p$ and $T$ stand respectively for pressure and temperature; the subscripts $v, l, w$ and sat refer to vapor, liquid, wall and saturated conditions. $\Delta T_{\text {cooling }}$ and $\Delta T_{\text {super-heating }}$ are the temperature difference linked respectively to the nucleation onset and boiling nucleation.

In a vertical bottom-heated mode PHP, for example, heterogeneous condensation may occur in the condenser region, where, reasonably, the wall temperature is lower than the vapor one. On the other hand, homogeneous condensation through the interface may occur in the evaporator region where vapor pressure may exceed the saturation point. Homogeneous condensation through the interface, indeed, takes place although the wall temperature is higher than the vapor one, which is a plausible situation in the evaporator region. Similar considerations can be made for evaporation.

Such kinds of phenomena occur simultaneously; however, in order to compute them, a hierarchical implementation has been considered. Therefore, for each time step, first heterogeneous phase changes are accounted for: the evaporative or condensed mass is estimated and the corresponding mass and energy balances are solved. Then, in the same time step, the homogeneous phenomena through the interface are considered and, again, the corresponding mass and energy balances are solved. Finally all the other phenomena (e.g. sensible heat exchange with the wall, axial conduction, etc.) are computed. For more details one should refer to the annex A reported in [30].

Note that the $1^{\text {st }}$ Adams-Bashforth integration scheme [31] has been adopted to integrate mass and energy balances if not differently indicated. 
Heterogeneous phase changes. Figure 3 shows in red the global control volume $(\mathrm{CV})$ adopted to solve mass and energy balances during heterogeneous condensation (A) and evaporation (B): it is closed, isochoric and diabatic with respect to the pipe walls. In case of condensation, it contains three sub-systems, one vapor $(V P)$ and two liquid elements $(L S)$ : the closed single vapor sub-domain allows a two-phase change and it is diabatic; the closed liquid sub-domains are mono-phase and adiabatic. The heterogeneous condensation will eventually occur in the vapor plug. In case of evaporation, $C V$ contains two vapor plugs and one liquid slug. Vapor sub-domains are closed, mono-phase and adiabatic, while liquid is closed and diabatic and allows two-phase changes. Thus, the heterogeneous evaporation will occur, eventually, in each liquid slice.

Accounting for the assumptions listed in the previous section (from 5 to 8), the integration of the mass and the energy balances written on $C V$ and on each $L S$ or $V P$ (see the annex A in [30]) leads to the definition of the evaporated or condensed mass, $m_{L V, \text { het }}$ :

$m_{L V, \text { het }}=\left|\frac{A_{w f} q_{w f}}{h_{L V}}\right| \Delta t$

where $A_{w f} q_{w f}$ is the heat transferred to or from the wall (section 2.3), $h_{L V}$ the heat of vaporization and $\Delta t$ the computational time step.

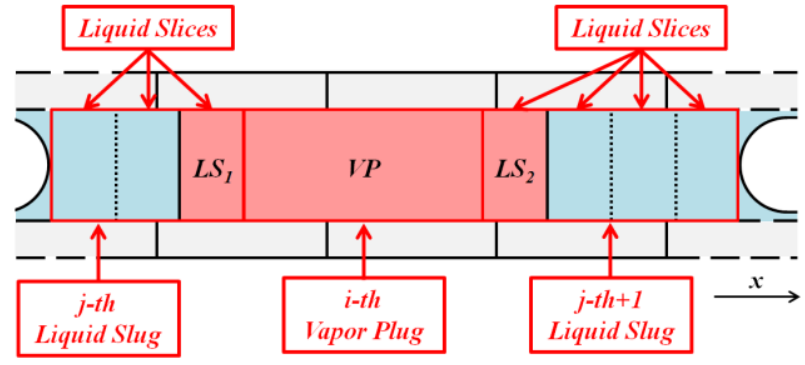

(A)

$\square$ Liquid Phase $\square$ Wall

$\square$ Vapor Phase $\square$ Control Volume

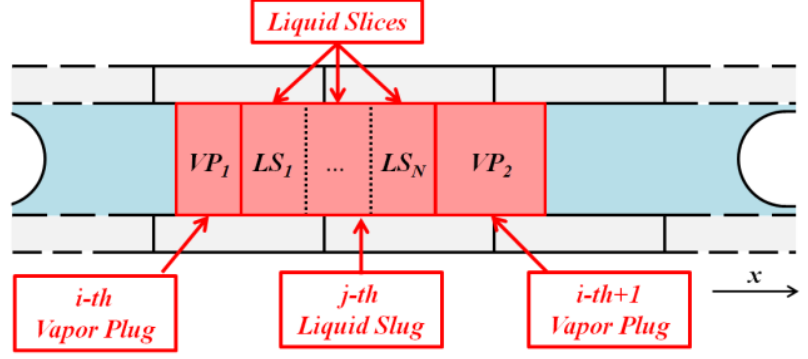

(B)

Liquid Phase $\square$ Wall

Vapor Phase $\square$ Control Volume

Fig. 3: Schematic of the control volumes CV (in red) adopted in case of heterogeneous condensation (A) or evaporation (B).

Note that heterogeneous phase changes may induce the formation of new fluidic elements, as well as the dimension rescaling of already existing liquid slugs and vapor plugs. A new element is produced only if $m_{L V}$ is higher than a minim value $m_{\min }$, otherwise mass exchange between adjacent elements occurs; $m_{\min }$ is computed as the mass of an equivalent sphere which fits perfectly within the tube $\left(m_{\text {min,eva(cond })}=\right.$ $\left.\frac{1}{6} \pi d_{i n}^{3} \rho_{v(l)}\right)$; finally, if $m_{L V}$ exceeds the mass of the corresponding element, this one vanishes and the adjacent slugs/plugs.

Homogeneous phase changes through the interface. Heterogeneous phase changes are computed for all the fluidic elements. Only at this point, on the new fluidic path, evaporation and condensation through the interface can take place ( $2^{\text {nd }}$ phase of the hierarchical numerical procedure). The adopted control volume $C V$ is shown in Fig. 3A; It is considered closed, adiabatic and isochoric. The two liquid slices and the vapor plug are open and adiabatic. However, if the control volume is adiabatic, it cannot be assumed that the phase changes are both isothermal and isobaric, thus only the assumption of $d P=0$ has been maintained (assumption 7).

As shown in [30], evaporated and condensed mass, $m_{L V, h o m}$, as well as the final length of the vapor elements, $V_{v, t+1}$, is calculated solving a simple linear systems of equations (Eq. 6) which accounts for the conservation of mass and volume (Fig. 4):

$$
\begin{gathered}
\text { Evaporation } \\
\left\{\begin{array} { c } 
{ m _ { L V , h o m } = | \Delta m _ { v } | _ { t _ { i } } ^ { t _ { i + 1 } } | } \\
{ V _ { v , t + 1 } = V _ { v , t } + \frac { m _ { L V , h o m } } { \rho _ { l } } }
\end{array} \quad \left\{\begin{array}{l}
m_{L V, h o m}=\left|\Delta m_{v}\right|_{t_{i}}^{t_{i+1}} \mid \\
V_{v, t+1}=V_{v, t}-\frac{m_{L V, h o m}}{\rho_{l}}
\end{array}\right.\right.
\end{gathered}
$$

where $V$ stands for volume and $\rho$ for density. 


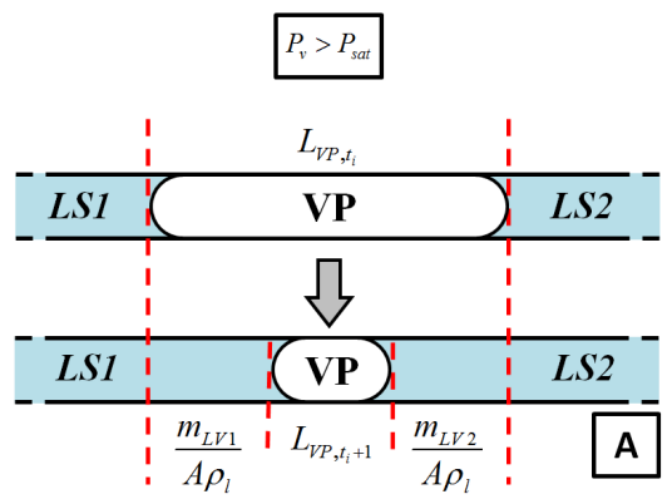

Liquid Phase

Vapor Phase

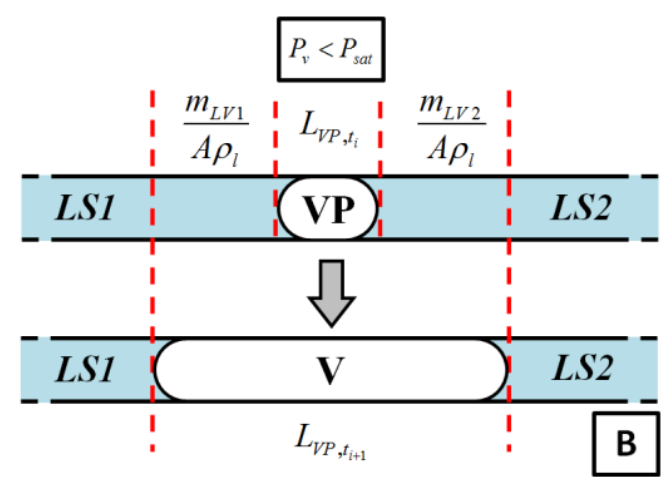

Liquid Phase $\square$ Vapor Phase

Fig. 4: Schematic of homogeneous condensation (A) and evaporation (B). Since the cross sectional area is constant, $V=A L$.

After the phase changes. In order to conclude the hierarchical procedure, mass and energy balances should be integrated accounting for all the other phenomena (e.g. sensible heat exchange with the wall, axial conduction, etc.). Note that the three steps of this procedure are occurring in sequence during the same time step $\Delta t$. The control volumes adopted this time consist of single vapor plugs or single liquid slices (see Fig. 5) representing closed domains.

Only one temperature is computed for each vapor plug because convection is greater than conduction for all the analyzed conditions, while liquid slugs are subdivided into smaller domains with constant length in order to increase the resolution in the representation of the energy field (Fig. 5). The energy equation is integrated making use of the $1^{\text {st }}$ Adams-Bashforth integration scheme if new elements are generated or old ones disappear in the time step, the $2^{\text {nd }}$ Adams-Bashforth integration scheme otherwise.
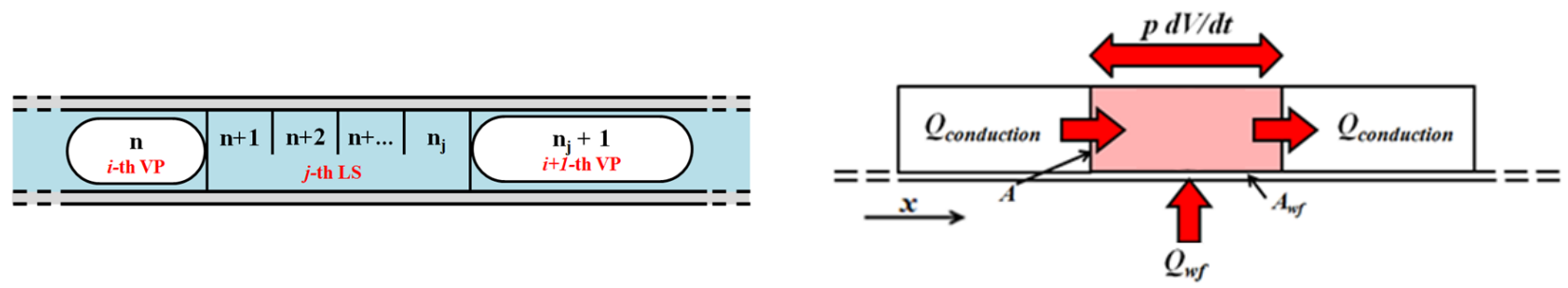

Fig. 5: Schematic of the liquid/vapor energy balance for the fluidic domains and sub-domains. VP stands for vapor plug, LS stands for liquid slug.

In a Lagrangian system, total time derivatives match ordinary time derivatives; thus, assuming constant specific heat $c_{V}$, the mass and the energy equations are:

$$
\begin{aligned}
& \frac{d m_{f, n}}{d t}=0 \\
& c_{V, f} m_{f, n} \frac{d T_{f, n}}{d t}=\left.\left(q_{w f, f} A_{w f}\right)\right|_{n}+\left(\left.k_{f} A \frac{\partial T_{f}}{\partial x}\right|_{n} ^{n-1}-\left.k_{f} A \frac{\partial T_{f}}{\partial x}\right|_{n+1} ^{n}\right)-P_{f, n} \frac{d V_{f, n}}{d t}
\end{aligned}
$$

where the subscript $f$ stands for fluidic, alternatively vapor or liquid; A is the cross sectional area (Fig. 5) while $k$ is the thermal conductivity.

As shown in Figure 5, the first term on the right side of the energy balance accounts for the sensible heat transferred between the wall and the fluid when no phase changes have occur previously; the second and the third terms are respectively the axial conduction within the fluid and the compression work computed only for vapor plugs.

\subsubsection{Momentum Equation}

The momentum equation has been solved directly for the global time step $\Delta t$ without accounting separately for phase changes; thus $d m \neq 0$ if evaporation or condensation has occurred; however it is a known quantity for all the liquid slugs. It is calculated for the liquid elements only, because friction between vapor plugs and wall elements is neglected (Assumption 3). Störmer-Verlet algorithm, in its velocity variant, has been applied to compute the velocity and the position at each time step because of its well known ability to 
capture the long term system dynamics in an accurate and stable way [32]. A Lagrangian approach has been adopted.

The momentum equation integrated along the $j$-th liquid slug length is:

$\frac{d\left(m_{l} w\right)}{d t}=m_{l} g \cos (\vartheta)+A\left(p_{i}-p_{i+1}\right)-0.5 f_{\tau} \frac{m_{l}}{d_{i n}} w|w|$

where $w$ is the liquid slug velocity and $d_{i n}$ the tube internal diameter.

The first term on the right side is the gravity force: $g$ is the gravity acceleration and $\vartheta$ is the local angle between the gravity vector and the flow direction. The second and the third terms are the forces respectively due to adjacent vapor expansion/compression (for the subscripts refer to Figure 1) and friction (viscous shear and minor losses due to bends and turns). Pressure drop due to capillary forces has been neglected ${ }^{1}$ because of the constant cross section along the tube length and because liquid menisci maintain hemi-spherical shape with zero contact angle at the wall (Assumption 4).

Viscous shear is treated semi-empirically. The friction coefficient $f_{\tau}$ is evaluated either for fully developed laminar (Hagen-Poiseuille, [33]) o turbulent flow (Haaland equation, [34]):

$f_{\tau}=\frac{64}{R e}$ $\operatorname{Re}<2000$

$\frac{1}{\sqrt{f_{\tau}}}=-1.8 \log _{10}\left[\left(\frac{\varepsilon}{3.7 d_{\text {in }}}\right)^{1.11}+\frac{6.9}{R e}\right] \quad R e \geq 2000$

where $\varepsilon$ is the tube internal surface roughness and $R e$ the local Reynolds number.

As suggested by Mameli et al. [23], minor losses are computed only if the liquid slug passes through at least a turn or a bend. The corresponding friction coefficient is evaluated according to Darby $3 \mathrm{~K}$ [35] method which empirical parameters $\left(K_{R e}, K_{d}\right.$ and $\left.K_{r}\right)$ are listed in Table 1:

$f_{\tau}=\frac{K_{R e}}{R e}+K_{r}\left[1+K_{d}\left(\frac{0.0254}{d_{\text {in }}}\right)^{0.3}\right]$

\begin{tabular}{c|c|c|c|c} 
Fitting type & $\boldsymbol{r}_{\text {turn }} / \boldsymbol{d}_{\text {in }}$ & $\boldsymbol{K}_{\boldsymbol{R} \boldsymbol{e}}$ & $\boldsymbol{K}_{\boldsymbol{r}}$ & $\boldsymbol{K}_{\boldsymbol{d}}$ \\
\hline Bend 90 $^{\circ}$ & 1.25 & 800 & 0.091 & 4 \\
Turn 180 & 1.25 & 1000 & 0.1 & 4
\end{tabular}

Tab. 1: Friction coefficients for bends and turns according to Darby $3 \mathrm{~K}$ method.

The velocity of each liquid slug is calculated by solving the momentum equation (Eq. 8), while their new position $x_{t}$ can be estimated as:

$x_{t}=x_{t-1}+w \Delta t+\frac{a}{2} \Delta t^{2}$

where $a$ is acceleration defined as the ratio between the applied forces and the slug mass.

\subsection{Solid/Fluid Coupling}

Solid and fluidic domains are related by means of the heat exchanged between the wall and the fluid, $q_{w f}$, which appears in all the energy balances (section 2.1 and 2.2.1). The wall domains are fixed in time (Eulerian approach), while the fluidic elements are moving (Lagrangian approach). Thus, a fluidic element may face different wall domains at each time step; in addition a wall element may face more than one fluidic element and vice versa (Fig. 6). Therefore, $q_{w f}$ is defined as:

\footnotetext{
${ }^{1}$ Even though the liquid/solid adhesion forces may be orders of magnitude lower with respect to the other terms in the momentum equation, in any case they may affect the fluid motion and the PHP start-up because they originate local instabilities at the menisci.
} 


$$
\left\{\begin{array}{l}
q_{w f, w}=\frac{1}{A_{w f}} \sum_{n=1}^{N_{f}} h\left(T_{w}-T_{n}\right) A_{w f, n} \\
q_{w f, f}=\frac{1}{A_{w f}} \sum_{k=1}^{N_{w}} h\left(T_{w, k}-T\right) A_{w f, k}
\end{array}\right.
$$

where $h$ is an appropriate heat transfer coefficient (HTC), $A_{w f}$ is the total area between the wall and the fluidic domains, while $A_{w f, n}$ and $A_{w f, k}$ represent the area in common between the $k$-th wall element and the $n$-th fluidic element.
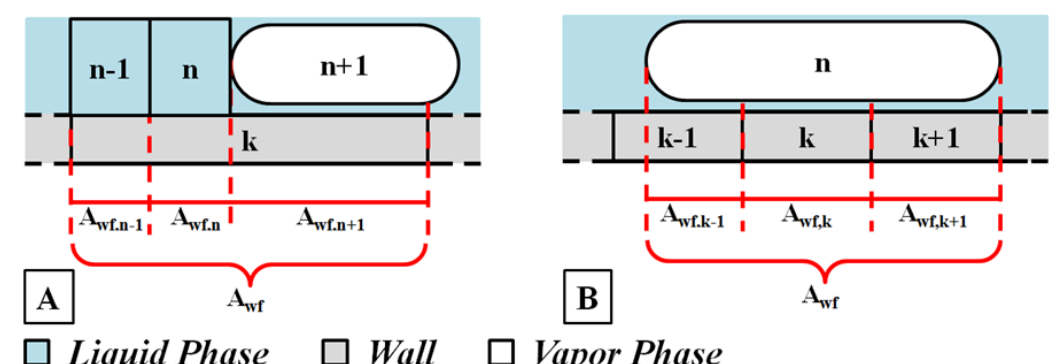

$\square$ Liquid Phase $\square$ Wall $\square$ Vapor Phase

Fig. 6: Definition of $A_{w f}, A_{w f, n}$ and $A_{w f, k}$ from the wall point of view (A) and from the fluid point of view (B).

If no phase changes occur, only sensible heat is transferred between solid and fluidic domains. In the case of liquid slugs, classical semi-empirical formula have been adopted even if they have not been developed for oscillating flow in mini-channels: Shah and London [36] correlation is implemented for the laminar flow thermally developing region (Eq. 13), the Gnielinski correlation [33] is used for the transient/turbulent flow (Eq. 14) while Dittus-Boelter correlation [33] is applied for the fully developed turbulent flow (Eq. 15).

$h=\left\{\begin{array}{lll}1.953 \frac{k}{d_{\text {in }}}\left(\operatorname{RePr} \frac{d_{\text {in }}}{L_{x}}\right)^{\frac{1}{3}} & \left(\operatorname{RePr} \frac{d_{\text {in }}}{L_{x}}\right) \geq 33.3 & R e \leq 2000 \\ \frac{k}{d_{\text {in }}}\left(4.364+0.0722 \operatorname{RePr} \frac{d_{\text {in }}}{L_{x}}\right) & \left(\operatorname{RePr} \frac{d_{\text {in }}}{L_{x}}\right)<33.3 & \end{array}\right.$

$$
2000<R e<10000
$$

$h=\frac{k}{d_{i n}}\left[\frac{\left(\frac{f_{\tau}}{8}\right)(R e-1000) \operatorname{Pr}}{1+12.7\left(\frac{f_{\tau}}{8}\right)^{\frac{1}{2}}\left(\operatorname{Pr}^{\frac{2}{3}}-1\right)}\right]$

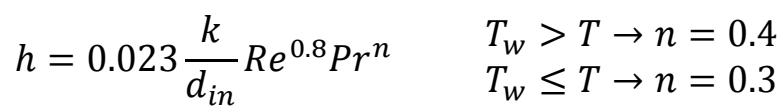

$R e \geq 10000$

where $\operatorname{Pr}$ is the Prandtl number and $L_{x}$ is the thermal entry length which has been set equal to the evaporator/adiabatic/condenser extent depending on the location of the $j$-th liquid slug.

The sensible heat exchanged between wall and vapor domains cannot be estimated by mean of the above reported classical correlations. The reason of that lies in the presence of the liquid film. Since the proposed model is mono-dimensional, it considers the liquid film constant in space and time (Assumption 9). Actually, some authors [19-20] report that the film dynamic may deeply influence the heat transferred by vapor plugs. Thus a fitting correlation has been adopted to fix the lack of modelling improving the calculation of the vapor sensible heat. Due to the large range of vapour slug velocities, with regimes where the bubble are almost in rest and others when the velocity may reach high values, both forced and natural convection are involved are assumed. Making use of the Buckingham theorem, the vapor-wall heat transfer coefficient has been described as function of both Reynolds and Rayleigh $(R a)$ numbers. When the velocity is null, the heat transfer coefficient is defined as constant, while as soon as the vapour slug is moving, its dynamic increases the effects of natural convection. For the same velocity, the hypergravity is increasing the heat transfer. The four fitting coefficients are estimated by comparison with experimental results in different operative conditions and under various gravity levels; $a$ is fitted at an external temperature of $293 \mathrm{~K}$, keeping a liquid film thickness constant of $50 \mu \mathrm{m}$. 


$$
\begin{aligned}
& h=h_{0}+a R e^{b} R a^{c} \quad h_{0}=200 \frac{W}{m^{2} K} \quad b=0.25 \\
& a=4 \frac{W}{m^{2} K} \quad c=0.4
\end{aligned}
$$

The term linked to the Reynolds number in Equation 16 is about $1500 \mathrm{~W} / \mathrm{m}^{2} \mathrm{~K}(\mathrm{Nu} \cong 130)$ at $1 \mathrm{~g}$ for a plug velocity of $1.5 \mathrm{~m} / \mathrm{s}$, i.e. it is dominating the constant value $\mathrm{h}_{0}=200 \mathrm{~W} / \mathrm{m}^{2} \mathrm{~K}(\mathrm{Nu} \cong 17)$. About the value of $\mathrm{h}_{0}$ with respect to the total sum for $h$, see also paragraph 3.2.

If phase change phenomena occur, then latent heat must be comprised and proper boiling/condensing HTCs must be defined. Since experimental correlations for oscillating evaporating/condensing menisci are missing, constant HTCs have been firstly considered (Eq. 17). Afterwards a sensitivity analysis has been performed to understand the influence of the chosen values on the model results: the maximum steady state temperature deviation was less than $0.5 \mathrm{~K}$ for boiling/condensing heat transfer coefficient ranging from 4000/2000 W/ $m^{2} K$, [3], to $30000 / 15000 \mathrm{~W} / \mathrm{m}^{2} \mathrm{~K}$. Indeed, the value of boiling/condensing HTCs does not influence deeply the PHP thermal performance because the most part of the heat is transferred by sensible ways only, as underlined by Shafii et al. [37]. The latent heat is prevalently the mechanical motor of the system, inducing phase change phenomena with the expansion and contraction of vapour slugs, and strong oscillation/circulation of the fluid within the channel.

$h= \begin{cases}10000 \frac{W}{m^{2} K} & \text { condensation } \\ 20000 \frac{W}{m^{2} K} & \text { evaporation }\end{cases}$

\subsection{Implementation}

The ordinary differential equations (ODE) system describing the physical model has been implemented and solved making use of the open source software GNU Octave. The computational time step is generally constant but if new elements are generated or old elements disappear, it is reduced of a magnitude in order to damp any possible unstable oscillation and it is gradually restored following a slope increment after 10 iterations. A sensibility analysis has been performed in order to understand the influence of the chosen time step on the model results: once it is small enough to guarantee numerical stability, the results are time step independent. For the tested conditions (section 3) a $\Delta t$ of $0.4 \mathrm{~ms}$ is the maximum allowable and, thus, it is chosen to minimized the total simulation time.

\section{NUMERICAL RESULTS}

The quasi-stationary ${ }^{2}$ and transient performances of a 16 turns PHP filled with FC-72 have been simulated under different gravity levels making use of the above described numerical model. The geometrical features of the tested device and the main code input parameters are listed in Table. 2.

\footnotetext{
${ }^{2}$ Quasi-steady state is experimentally reached when all the temperature signals show an average value constant in time.
} 


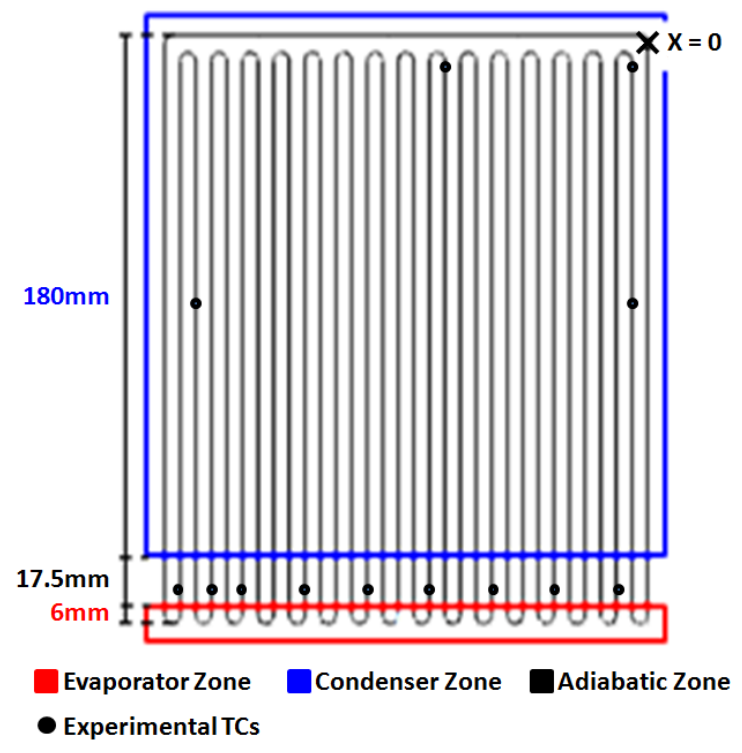

\begin{tabular}{lr}
\hline Input parameter & Value \\
\hline Working fluid & FC-72 \\
Volumetric filling ratio & 0.5 \\
Tube material & Copper \\
Internal diameter & $1.1 \mathrm{~mm}$ \\
External diameter & $2.0 \mathrm{~mm}$ \\
Surface roughness & $50 \mu \mathrm{m}$ \\
Total length & $6.62 \mathrm{~m}$ \\
$\mathrm{~N}^{\circ}$ of evaporator bends & 16 \\
External temperature & $21^{\circ} \mathrm{C}$ \\
$*$ External heat transfer coefficient & $\mathrm{W} / \mathrm{m}^{2} \mathrm{~K}$ \\
$*$ Film Thickness & $50 \mu \mathrm{m}$ \\
$* \Delta T$ superheat & $2.5^{\circ} \mathrm{C}$ \\
$* \Delta T$ cooling & $0.01^{\circ} \mathrm{C}$ \\
$* \mathrm{~N}^{\circ}$ of slug/plug at $t=0$ & 20 \\
$* \mathrm{~N}^{\circ}$ of wall grids & 400 \\
\hline mental data; other unknown values has been guessed in feasible
\end{tabular}

* The value of the external HTC has been estimated from experimental data; other unknown values has been guessed in feasible ranges. Sensitivity analyses shown independency of the model results.

Tab. 2:Features of the tested PHP. Geometrical, physical and numerical input parameters. Experimental TCs locations are also indicated.

The numerical results have been compared with the experimental data from normal gravity and hyper-gravity test obtained on the ESA-ESTEC Large Diameter Centrifuge (LDC) during the ESA SYT!2013 campaign [8]. Experiments have been conducted both on horizontal and vertical Bottom Heated Mode (BHM) configuration. Even if data are available up to $20 \mathrm{~g}, 2 \mathrm{~g}$ is the maximum simulated hyper-gravity level. In fact the proposed numerical model is, indeed, applicable only to a confined operating regime (i.e. slug flow). In order to satisfy this assumption, the static fluid confinement criterion [38] should be satisfied:

$B o=\frac{g\left(\rho_{l}-\rho_{v}\right) d_{i n}^{2}}{\sigma} \leq 4$

The critical diameter for the FC-72 obtained transposing Eq. 18 and imposing $B o\left(d_{c r}\right)=4$ is shown in Fig. 7 as a function of temperature at different acceleration levels. The actual PHP internal tube diameter, $d_{i n}$, is represented in dashed line: if the critical diameter, $d_{c r}$, is less than the actual diameter, the fluid may not be in a confined region and stratification may occur. For the tested PHP, theoretically, this transition should occur between $2 \mathrm{~g}$ and $3 \mathrm{~g}$. We stress that this criterion is valid for s slug flow at rest and, as soon as there is a motion, Reynolds and Capillary numbers should be considered, since a dynamic deformation of the liquid plug is possible.

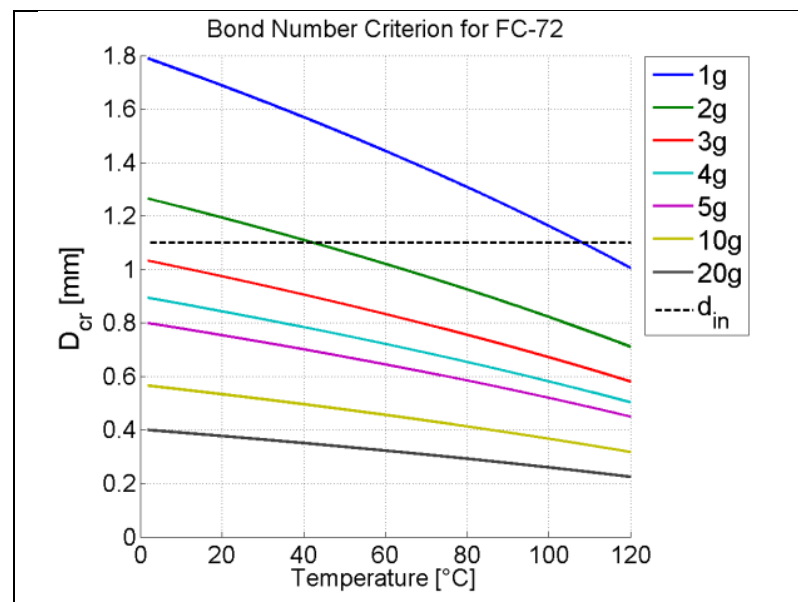

Fig. 7: Critical internal diameter $\left(B o\left(d_{c r}\right)=4\right)$ as function of temperature at different acceleration levels for the FC-72.

The experimental apparatus is equipped with a pressure transducer plugged in the condenser zone and $14 \mathrm{~T}$ thermocouples (TCs), 9 located $6 \mathrm{~mm}$ above the evaporator zone, 4 in the condenser region and one is measuring the external temperature. Thus, the results are presented mainly in terms of local spatial average 
temperature and pressure time evolutions. The fluid pressure or the tube wall temperature trends are shown together with the heat input level on the secondary y-axis and, in case of the LDC test, with the gravity acceleration which is reported directly over the plot line. Note that the experimental evaporator TCs are not exactly located in the hot section, but just above it, actually in the adiabatic zone, because of the presence of the electrical heating wire. In order to be coherent with the model described in section 2, the temperatures recorded by these TCs should be compared with the ones computed in the above mentioned adiabatic region. Therefore, experimental evaporator temperatures will be referred in the following as adiabatic temperatures.

\subsection{Vertical configuration}

\subsubsection{Ground tests}

Ground tests have been performed increasing the heat input from $50 \mathrm{~W}$ to $100 \mathrm{~W}$ with an intermediate step at $70 \mathrm{~W}$. The starting heat input level is kept for 16 minutes while the following are kept for 8 minutes.

Figure 8 shows the comparison in term of local spatial average wall temperature between the experimental and numerical results. The red line indicates the mean temperature in the evaporator zone, the gray line in the adiabatic region and the blue line in the condenser. The standard deviation at each time step of the experimental results is also reported as a colored range over the solid line. It is clearly visible that the model is able to reproduce the experimental data for all the tested conditions. The maximum error in term of wall temperature is less than $6 \%$; in addition the numerical temperatures fit within the experimental dispersion range, a part for the $70 \mathrm{~W}$ results that are little over-estimated.

The model is also able to reproduce the transition of about 10 s between the different operative conditions (power levels) clearly visible for the adiabatic temperatures; the dynamic of the condenser, on the other hand, seems to not be correctly reproduced. However this was expected since the experimental results are influenced by the presence of the heat sink, with high heat capacity, and, thus, high thermal inertia, while the model is not accounting for the heat sink presence and considers only the PHP serpentine. Thus the numerical dynamic at the condenser is, obviously, more rapid. For the same reason, an under-prediction of the start up time appears in the predicted results
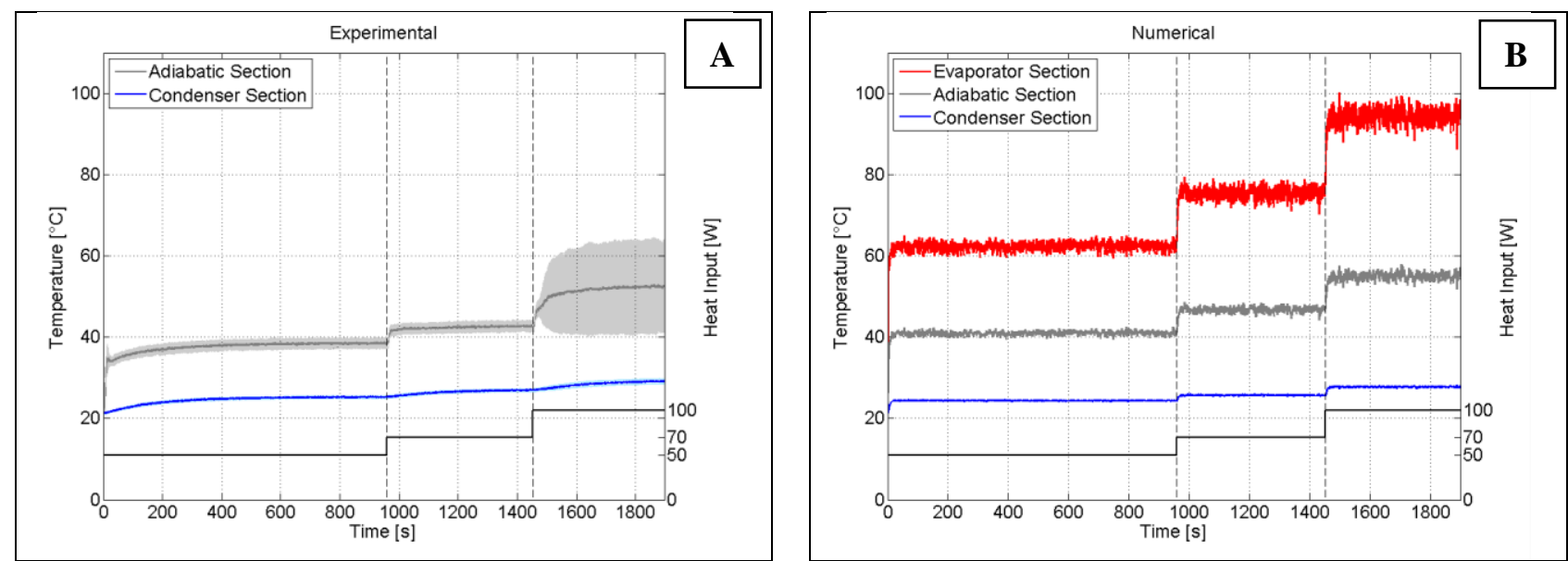

Fig. 8: Comparison between experimental (A) and numerical (B) wall temperatures for the BHM PHP at different heat inputs in normal gravity (ground test). The solid lines represent the local spatial average wall temperature, while the colored ranges on the experimental results indicate the standard deviation on the recorded data. 

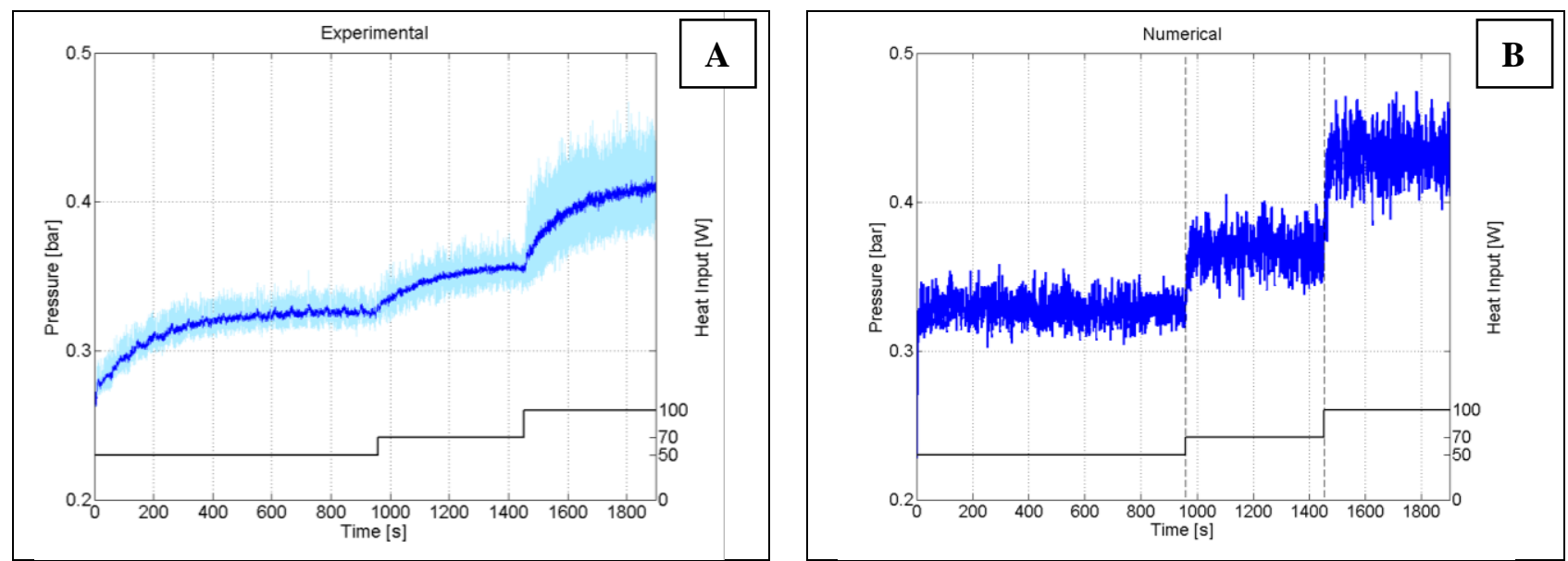

Fig. 9: Comparison between experimental (A) and numerical (B) pressure for the BHM PHP at different heat inputs in normal gravity (ground test). The solid lines represent the filtered data, while the colored ranges on the experimental results indicate the non filtered recorded pressure.

Figure 9 shows the comparison between experimental and numerical data in term of pressure. Again the model is able to reproduce the experimental results: the maximum error on the computation, estimated at quasi steady-state ${ }^{3}$, is less than $1.5 \%$; also the oscillation amplitude is reproduced.

The transient time is, on the other hand, strongly underestimated. Since the fluid and the thermal dynamic of PHPs are strictly connected, a so evident error appears not justifiable. Experimental issues may have influenced the results: first of all the position of the pressure sensor is not completely appropriate, since being the sensor plugged outside the condenser section, the pressure signals may be damped and/or delayed; secondly, the recorded pressure is influenced by the temperatures at the condenser, $p=f(\rho, T)$, which dynamics is influenced by the heat sink, which is not directly modeled. In addition, the Fast Fourier Transform (FFT) analysis performed on both the experimental and numerical signals does not indicate any dominant frequency, underling that the model is not introducing spurious neither artificial dynamics when the vertical configuration is simulated (Fig. 10).
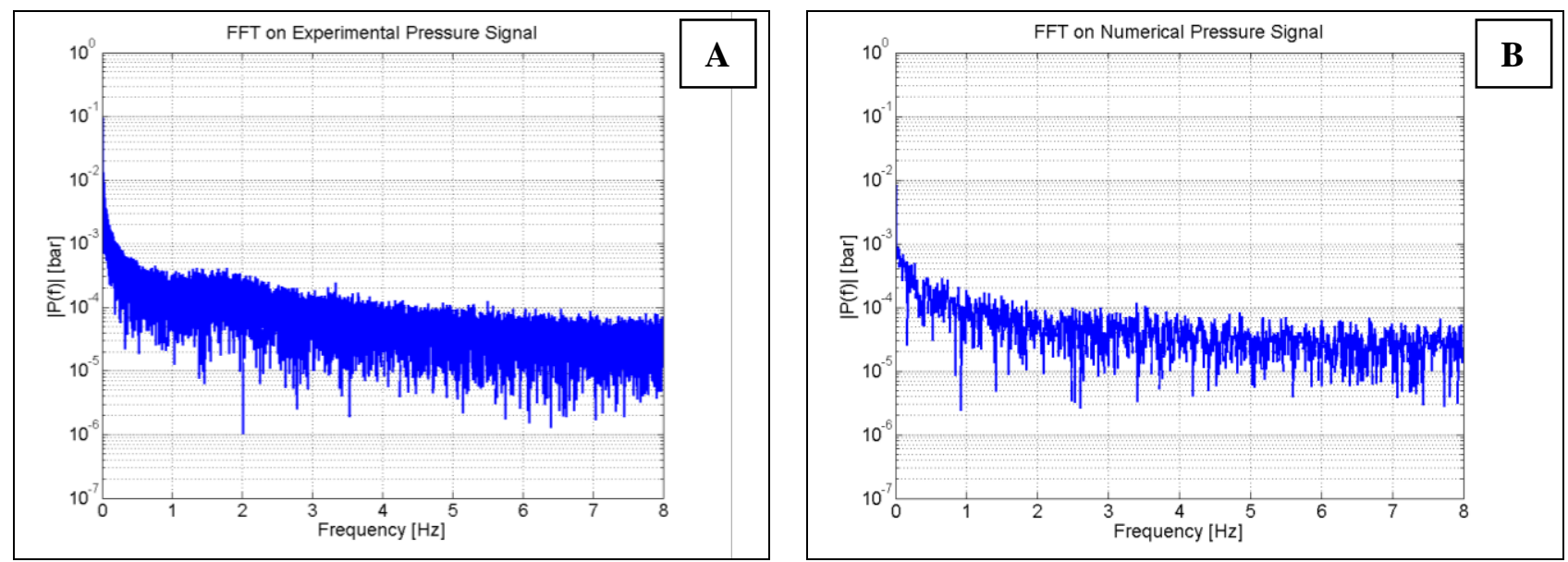

Fig. 10: FFT analysis performed on experimental (A) and numerical (B) pressure signal.

\subsubsection{Hyper-gravity tests}

Taking the PHP in the vertical position, tests have been carried out on the LDC at ESA-ESTEC by changing both the heat input and the gravity level: the device is started up at $50 \mathrm{~W}$ in normal gravity conditions till the temperature steady state is reached, then the gravity level is increased and the same heating cycle (50, 70 and $100 \mathrm{~W}$ ) of the ground test is performed; finally the device is shut down. The comparison between experimental and numerical results is reported in Fig. 11.

\footnotetext{
${ }^{3} 100\left(\left|\bar{p}_{\text {exp }}-\bar{p}_{\text {num }}\right|\right) / \bar{p}_{\text {exp }}$
} 

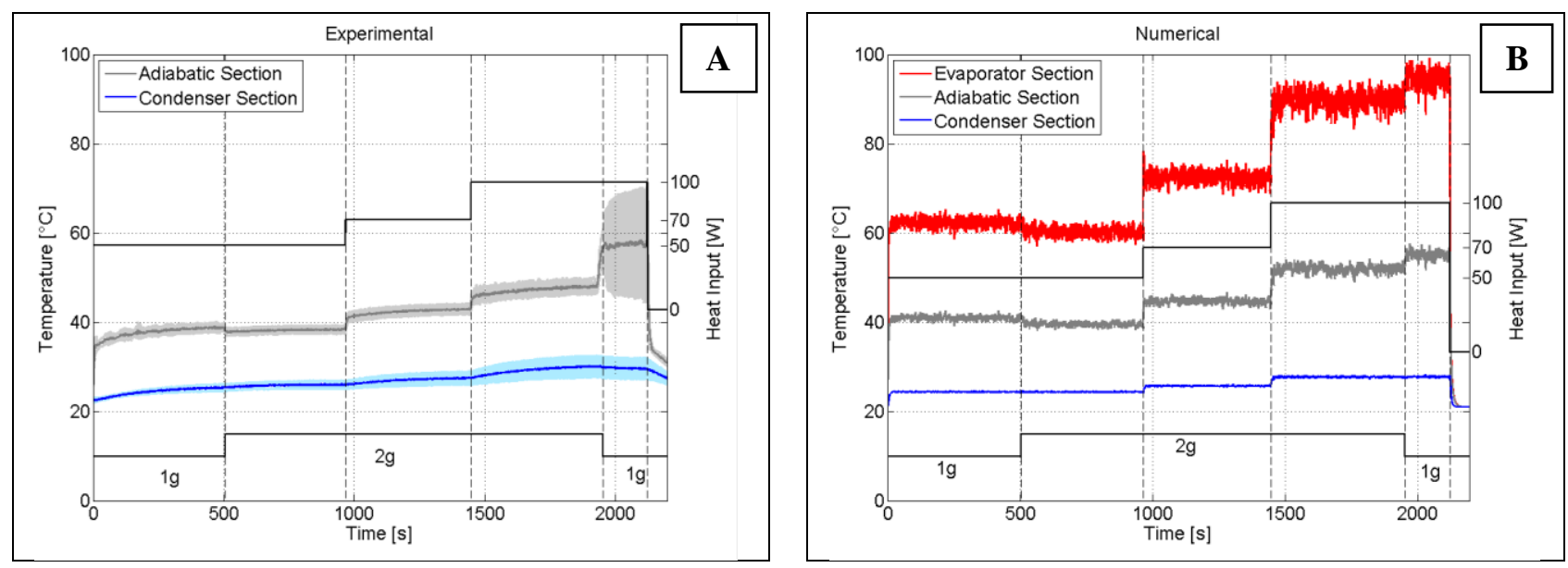

Fig. 11: Comparison between experimental (A) and numerical (B) wall temperatures for the BHM PHP at different heat inputs and gravity levels. The solid lines represent the local spatial average wall temperature, while the colored ranges on the experimental results indicate the standard deviation on the recorded data.

When the PHP is oriented in the vertical bottom heated position, the acceleration vector is parallel to the flow path, from the condenser to the evaporator zone. Thus, gravity helps the liquid flowing back from the condenser to the evaporator section; this, theoretically, enhances the whole fluidic motion. The experimental data, indeed, show that the PHP is working with slightly better thermal performance at $2 \mathrm{~g}$ : the average evaporator temperature can be directly compared between $1 \mathrm{~g}$ and $2 \mathrm{~g}$ for $50 \mathrm{~W}$ and $100 \mathrm{~W}$ and in both cases the temperature is evidently lower. The same behavior, both in term of temperature levels and transient time, is successfully predicted by the numerical model. The maximum error on the temperature calculation is always less than $6 \%$.

Figure 12 shows the temperature transition from an already stationary situation at normal gravity to hypergravity $(2 \mathrm{~g})$ conditions for $50 \mathrm{~W}, 70 \mathrm{~W}$ and $100 \mathrm{~W}$. The fluidic element are moving within the PHP oscillating and circulating. If the circulation velocity increases, the performances of the PHP are enhanced because of the higher efficiency in transporting heat from the hot to the cold zone.

Theoretically, the increment of gravity should enhance the circulation of the fluid for a bottom heated PHP. Eventually, the number of full laps travelled by the fluidic elements and calculated from $t=t 0$ ( 0 in the graphs) are plotted versus time in Fig. 13, both in term of mean value (solid line) and dispersion (colored range). For example at $50 \mathrm{~W}$, on average, the fluidic elements perform 3.5 full laps between $0 \mathrm{~s}$ and $300 \mathrm{~s}$. The slope associated to each interpolating red curve reported in Fig. 13 represents the circulation frequency of the fluid in the analyzed conditions. For example, taking the case at $50 \mathrm{~W}$, at normal gravity the mean circulation frequency of the fluid is about $0.73 \mathrm{rpm}$. As expected, in all the three tested cases, the circulation frequency, and thus the velocity, increases when passing from $1 \mathrm{~g}$ to $2 \mathrm{~g}$ : the frequency value varies from $0.73 \mathrm{rpm}$ to $1.07 \mathrm{rpm}$ in the case of $50 \mathrm{~W}$, from $0.56 \mathrm{rpm}$ to $1.41 \mathrm{rpm}$ at $70 \mathrm{~W}$ and from $0.76 \mathrm{rpm}$ to $1.41 \mathrm{rpm}$ at $100 \mathrm{~W}$.
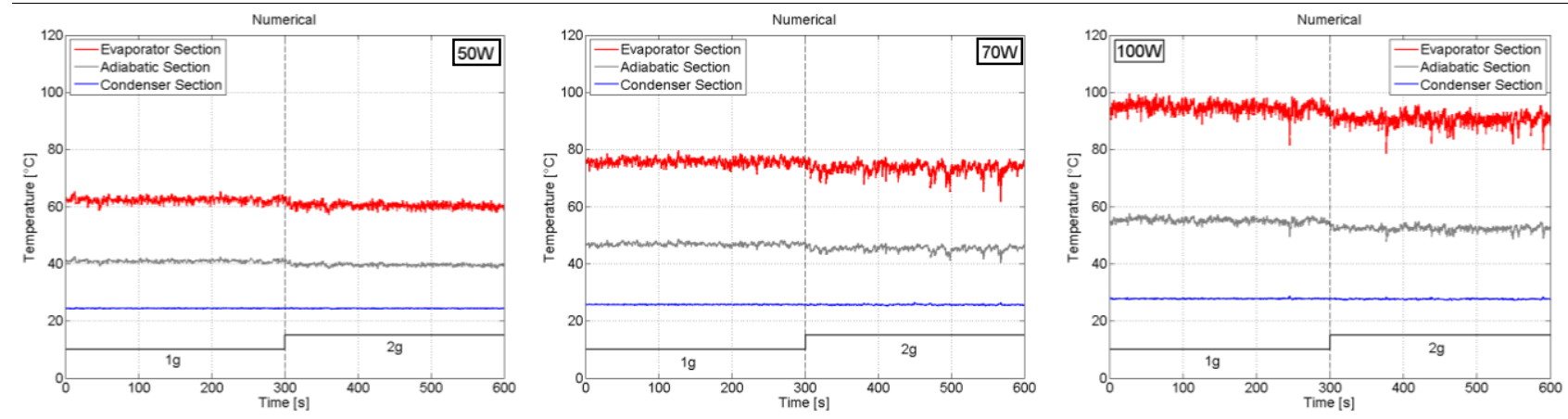

Fig. 12: BHM PHP, spatial average wall temperature at $50 \mathrm{~W}, 70 \mathrm{~W}$ and $100 \mathrm{~W}$. Effect of the gravity change from $1 \mathrm{~g}$ to $2 \mathrm{~g}$. 

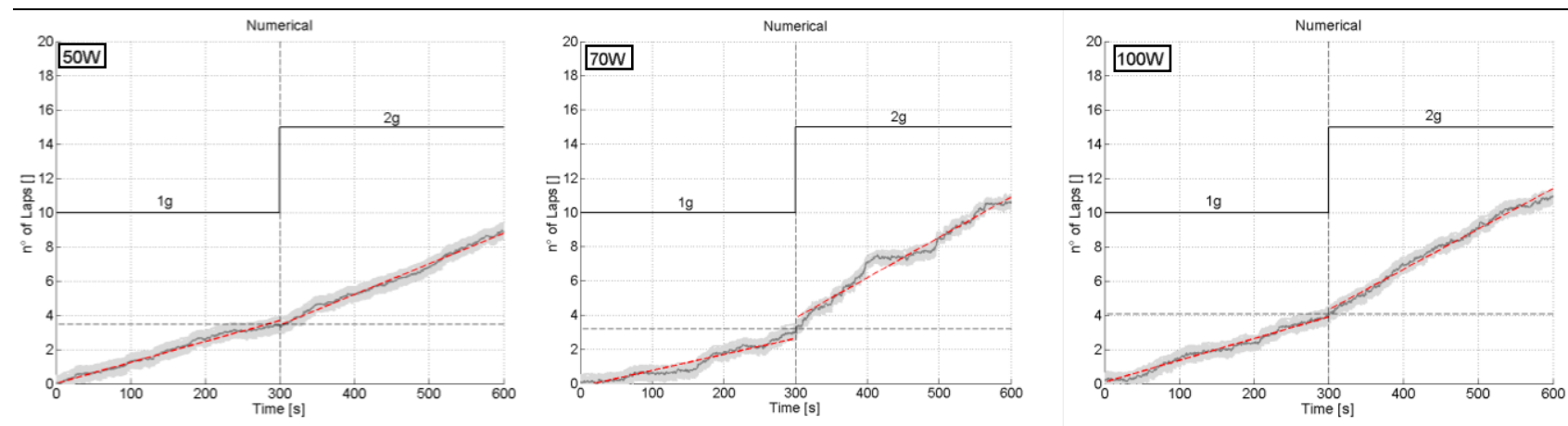

Fig. 13: BHM PHP, number of round in time at $50 \mathrm{~W}, 70 \mathrm{~W}$ and $100 \mathrm{~W}$ both in term of mean value (solid line) and dispersion (colored range). Effect of the gravity change from $1 \mathrm{~g}$ to $2 \mathrm{~g}$. Red dotted lines report the linear interpolation curves.

\subsection{Horizontal configuration}

As for the vertical case, ground tests on the horizontal configuration have been performed increasing the heat input from $50 \mathrm{~W}$ to $100 \mathrm{~W}$ with an intermediate step at $70 \mathrm{~W}$. The starting heat input level is kept for 16 minutes while the following are kept for 8 minutes. Figure 14 shows the comparison in term of pressure signals between the experimental and numerical results.
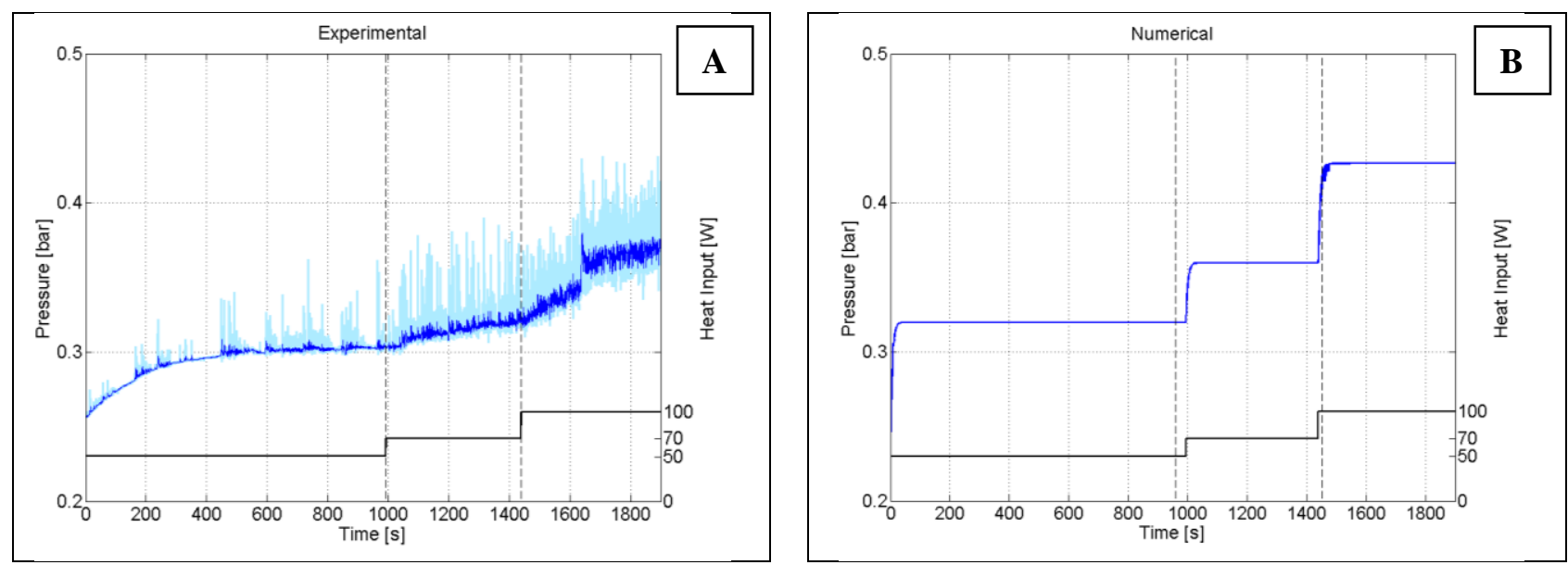

Fig. 14: Comparison between experimental (A) and numerical (B) pressure for the horizontal PHP at different heat inputs in normal gravity (ground test). The solid lines represent the filtered data, while the colored ranges on the experimental results indicate the non filtered recorded pressure.

The above reported figure shows that the model is not able to reproduce the pressure data when the PHP is placed in horizontal position. Specifically, the numerical signal is not oscillating, a part for few sporadic events during the power transitions. The same behaviour is detectable in the computed velocities (Fig. 15): the fluid within the horizontal device, indeed, starts moving, but after some time it stops reaching an equilibrium condition. Although the experimental velocities have not been measured as well as no visualization of the internal motion is available, if the fluid within the tube does not oscillate the recorded temperature should be much higher that the recorded data (Fig. $16 \mathrm{~A}$ ), since the heat would be transferred only by conduction mainly in the wall domain. Therefore, the model appears not to be able to simulate the dynamic of the fluid when the PHP is horizontal. In fact the numerical method may damp the fluid oscillations, since the Verlet algorithm, chosen because of its well known ability to capture the long term system dynamics in an accurate and stable way, strongly acts on the liquid motion quantities avoiding any possible instability at the base of the fluid oscillations; in addition, the homogeneous phase changes computed after the heterogeneous ones soften the localized pressure picks experimentally observed, which are the principal responsible of the fluid oscillations for an horizontal PHP, further reducing the global fluidic oscillations. The vertical configuration does not suffer this problem since the presence of gravity, the main actor when the PHP is placed in vertical mode, opposes such kind of spurious and unphysical stabilization. 


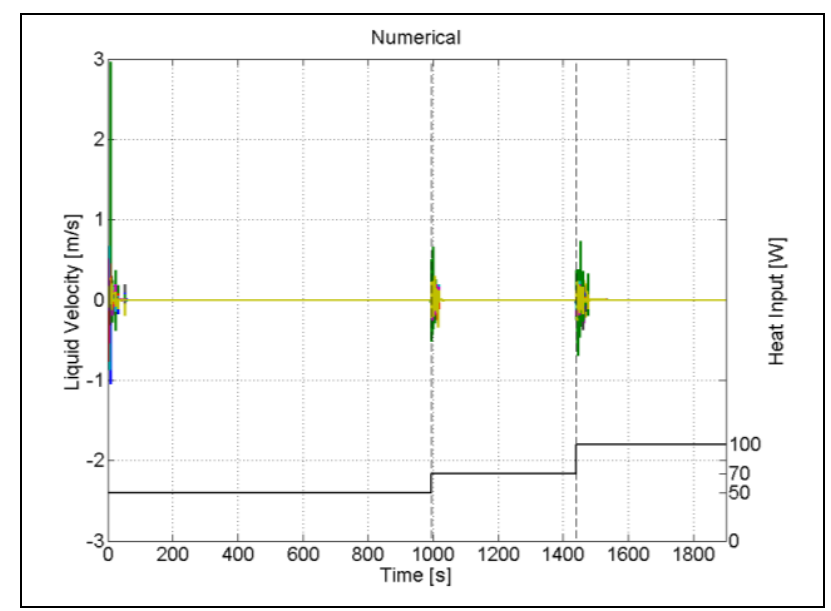

Fig. 15: Numerical liquid slugs computed velocities; different colours indicate different fluidic elements. The instabilities originated by modifications in the operative conditions are quickly recovered inducing equilibrium state of the fluid.

Noteworthy, since Equation 16 has been introduced and fitted in order to overcome the lack of empirical formulas in the computation of the sensible HTC between vapor elements and wall domains, such fitting allows gaining, also for the horizontal configuration, the correct temperature trend (Fig 16), even if the internal dynamic is wrongly computed. This means that the term $h_{0}$, which is the most influential value in Equation 16 when the fluid is at rest, i.e. for horizontal conditions, has been over-estimated (and so the corresponding sensible HTC at rest) while the multiplier $a$, which assumed importance during convection, has been, proportionally, under-estimated in order to allow the temperature prediction also at all the other gravity levels when the fluid is actually moving within the device.
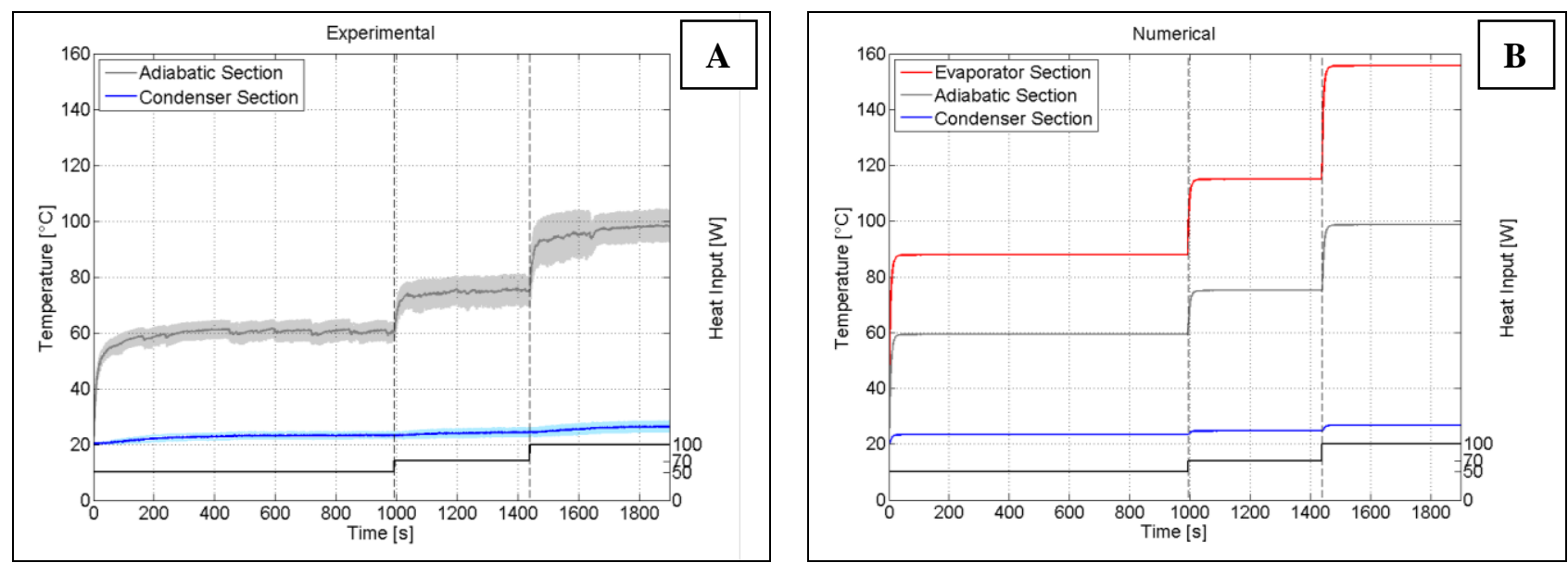

Fig. 16: Comparison between experimental (A) and numerical (B) wall temperatures for the horizontal PHP at different heat inputs in normal gravity (ground test). The solid lines represent the local spatial average wall temperature, while the colored ranges on the experimental results indicate the standard deviation on the recorded data.

\section{CONCLUSIONS}

A novel 1-D lumped parameter code for steady and transient simulations of Pulsating Heat Pipes has been proposed. With the suppressing of the standard assumption of saturated vapor plugs and the consequent embedding of heterogeneous and homogeneous phase changes through the interface, directly evaluated by means of a proper hierarchical procedure, this model represents now a step forward for the PHP design. In addition, to account for the influence of the liquid film on the conjugate heat transfer, a novel correlation for the estimation of the wall/vapor sensible HTC has been introduced and tuned up by comparison with experimental data. The model has been validated in several operative conditions and under various gravity levels by comparison with experimental data achieved on a planar copper PHP (horizontal and BHM configuration) partially filled with FC-72 tested both in normal and hyper-gravity (ESA-ESTEC LDC) conditions. According to the Bond number criterion, the tested PHP is guaranteed to work in a confined mode only for gravity levels less than $2 \mathrm{~g}$. In the case of vertical operation, the thermal performance of the PHP, both in term of temperature value and transient time, are well reproduced. The maximum error on the temperature prediction is less than $6 \%$. In addition, the model is able to predict the internal dynamic of the 
fluid. The simulated pressure trend is aligned with the experimental data with a little over-prediction (maximum error less than 1.5\%). The FFT analysis performed on both the experimental and numerical signals does not indicate any dominant frequency, underling that the model in not introducing artificial dynamics. When the PHP is oriented in BHM, the acceleration vector is parallel to the flow path, directed from the condenser to the evaporator zone. Thus, gravity helps the liquid flowing back from the condenser to the evaporator section, improving the device performance. The model shows that at $2 \mathrm{~g}$ the circulation frequency increases of respectively 1.5, 1.8 and 2.5 times depending on the power level $(50 \mathrm{~W}, 70 \mathrm{~W}, 100 \mathrm{~W})$. Although the model represents, at the moment, an already fairly good tool for designing a capillary CLPHP, there are still possible improvements, since, for example, in horizontal mode, it predicts the temperature behavior, but not yet correctly simulates the internal dynamics, such as short oscillations of liquid slugs. The numerical procedure adopted for the integration of the motion quantity equation as well as the phase changes phenomena, artificially stabilize the fluid motion dampening any possible dynamic. Moreover the film thickness remains a fixed value, which should be modeled and compared with experimental results. The liquid film dynamic is, indeed, essential to correctly reproduce the vapor conjugate heat transfer, as well as dry-out phenomena which may occur at high heat fluxes limiting the feasible applications of PHPs. Moreover, the vapor/wall HTC has been tuned against experimental data from FC-72 only: comparison with other working fluids should be performed. In addition this tuning equation is, probably, affected by an overestimation of the $h_{0}$ coefficient and a consequent under-estimation of the multiplier $a$;. Finally the start up phase and the dynamic of the temperature at the condenser side should be improved considering the thermal inertia of some peripheral experimental devices and the transition between different flow patterns should be implemented in order to surpass the strong common simplification of slug flow. After the start-up phase, the Bond number criterion alone may not be sufficient to define the fluid confinement; when the fluid motion is activated, inertial and viscous effects may be dominant over the capillarity depending on the liquid and vapor interfacial velocity. The Garimella criterion [39] applied to the above tested PHP states that, if gravity acts, as soon as the fluid starts moving, perfect slug flow is not anymore vouched for, underling the criticality of the above mentioned assumption.

\section{ACKNOWLEDGEMENTS}

The present work has been carried out in the framework of the project ESA-AO-2009 "Microgravity investigations of a novel two phase thermal management device for the ISS" financed by the Italian Space Agency (ASI-DOLFIN-II). The authors acknowledge the support of the European Space Agency through the MAP Condensation program (MAP ENCOM, AO-2004-096) as well as NOVESPACE team in Bordeaux and Dr. Vladimir Pletser from ESA for his support and encouragement in the parabolic flight campaign. A thanks is needed to ESA's Spin You Thesis!2013 organizers and LIS engineers for the support in the hypergravity experimental campaign, as well as to the M.Sc. thesis student Corrado Roncelli for his help in the experimental assessment. Thank to Dr. Olivier Minster and Dr. Balazs Toth for their interest and support to the PHP activities. In particular a thanks is due to Dr. Vadim Nikolayev for the very fruitful discussion regarding the phase changes modeling. Finally the authors acknowledge Prof. Miltos Petridis and the School of Computing, Engineering and Mathematics of the University of Brighton for the financial support.

\section{NOMENCLATURE}

\begin{tabular}{ll}
\multicolumn{2}{l}{ Latin symbols } \\
\hline$A$ & Cross flow area, $\left[\mathrm{m}^{2}\right]$ \\
$A_{e x}$ & External lateral area, $\left[\mathrm{m}^{2}\right]$ \\
$A_{w f}$ & Internal lateral area, $\left[\mathrm{m}^{2}\right]$ \\
$a$ & Acceleration, $\left[\mathrm{ms}^{-2}\right]$ \\
$c_{V}$ & Specific heat constant volume, $\left[\mathrm{Jkg}^{-1} \mathrm{~K}^{-1}\right]$ \\
$d_{i n}$ & Diameter, [m] \\
$f_{\tau}$ & Friction coefficient, [] \\
$g$ & Gravity acceleration, $\left[\mathrm{ms}^{-2}\right]$ \\
$h$ & Convection coefficient, $\left[\mathrm{Wm}^{-2} \mathrm{~K}^{-1}\right]$ \\
$h_{l}$ & Liquid specific enthalpy, $\left[\mathrm{Jkg}^{-1}\right]$
\end{tabular}

\begin{tabular}{ll}
$w$ & Velocity, $\left[\mathrm{ms}^{-1}\right]$ \\
$x$ & Axial coordinates, $[\mathrm{m}]$ \\
$y$ & Axial coordinates, $[\mathrm{m}]$ \\
Greek & symbols \\
\hline$\Delta t$ & Time step, $[\mathrm{s}]$ \\
$\varepsilon$ & Surface roughness, $[\mathrm{m}]$ \\
$\vartheta$ & Inclination to horizontal, $[\mathrm{rad}]$ \\
$\rho$ & Density, $\left[\mathrm{kg} / \mathrm{m}^{3}\right]$ \\
$\sigma$ & Surface tension, $\left[\mathrm{Nm}^{-1}\right]$ \\
Subscripts \\
\hline$f$ & Fluidic
\end{tabular}




\begin{tabular}{|c|c|c|c|}
\hline$h_{v}$ & Vapor specific enthalpy, $\left[\mathrm{Jkg}^{-1}\right]$ & hom & Homogenous phase change \\
\hline$h_{L V}$ & Latent heat of vaporization, $\left[\mathrm{Jkg}^{-1}\right]$ & het & Heterogeneous phase change \\
\hline$k$ & Thermal conductivity, $\left[\mathrm{Wm}^{-1} \mathrm{~K}^{-1}\right]$ & $l$ & Liquid \\
\hline$L$ & Length, $[\mathrm{m}]$ & sat & Saturated conditions \\
\hline$L_{x}$ & Thermal entry length, $[\mathrm{m}]$ & $v$ & Vapor \\
\hline$m$ & Mass, $[\mathrm{kg}]$ & $w$ & Wall \\
\hline$m_{L V}$ & Evaporated/Condensed mass, $[\mathrm{kg}]$ & $\infty$ & Environmental \\
\hline$N$ & Number of elements, [] & \multicolumn{2}{|c|}{ Acronyms } \\
\hline$N u$ & Nusselt number, [] & ANN & Artificial Neural Networks \\
\hline$p$ & Pressure, $[\mathrm{Pa}]$ & $\mathrm{BHM}$ & Bottom Heated Mode \\
\hline $\operatorname{Pr}$ & Prandtl number, [] & CFD & Computational Fluid Dynamics \\
\hline$Q$ & Heat power, $[\mathrm{W}]$ & $\mathrm{CV}$ & Control Volume \\
\hline$q_{e x}$ & External heat flux, $\left[\mathrm{Wm}^{-2}\right]$ & ESA & European Space Agency \\
\hline$q_{w f}$ & Heat flux between wall and fluid, $\left[\mathrm{Wm}^{-2}\right]$ & FFT & Fast Fourier Transform \\
\hline$R^{*}$ & Gas constant, $\left[\mathrm{Jkg}^{-1} \mathrm{~K}^{-1}\right]$ & HTC & Heat Transfer Coefficient \\
\hline$R a$ & Rayleigh number, [] & LDC & Large Diameter Centrifuge \\
\hline$R e$ & Reynolds number, [] & LS & Liquid Slug \\
\hline$T$ & Temperature, $[\mathrm{K}]$ & ODE & Ordinary Differential Equations \\
\hline$t$ & Time, $[\mathrm{s}]$ & PHP & Pulsating Heat Pipe \\
\hline$U$ & Internal energy, $[\mathrm{J}]$ & $\mathrm{TC}$ & Thermocouple \\
\hline$u$ & Specific internal energy, $\left[\mathrm{Jkg}^{-1}\right]$ & VP & Vapor Plug \\
\hline$V$ & Volume, $\left[\mathrm{m}^{3}\right]$ & & \\
\hline
\end{tabular}

\section{REFERENCES}

[1] Akachi, H. (1990). US Patent No. 4921041.

[2] Akachi, H. (1993). US Patent No. 5219020.

[3] Mameli, M., Marengo, M., \& Khandekar, S. (2014). Local heat transfer measurement and thermo-fluid characterization of a pulsating heat pipe. Int. J. of Thermal Sciences, 45, 140-152.

[4] Kiseev, V.M., \& Zolkin, K.A. (1999). The influence of acceleration on the performance of oscillating heat pipe. Proc. of the 11th International Heat Pipe Conference.

[5] Van Es, J., \& Woering, A.A. (2000). High-acceleration performance of the flat swinging heat pipe. NLR-TP-2000-265.

[6] Gu, J., Kawaji, M., \& Futamaca, R. (2004). Effect of gravity on the performance on pulsating heating pipe. J. of Thermophysics and Heat Transfer, 18, 370-378.

[7] Gu, J., Kawaji, M., \& Futamata, R. (2005). Microgravity performance of micro pulsating heat pipe, Microgravity Sci. Technol, 16, 181-185.

[8] Mameli, M., Manzoni, M., Araneo, L., Filippeschi, S., \& Marengo, M. (2014). Pulsating heat pipe in hyper-gravity conditions. Heat Pipe Science and Techonology, an International Journal. ACCEPTED FOR PUBLICATION.

[9] Mameli, M., Araneo, L., Filippeschi, S., Marelli, L., Testa, R., \& Marengo, M. (2014). Thermal response of a closed loop pulsating heat pipe under variable gravity field, Int. J. of Thermal Sciences, 80, 11-22.

[10] Mameli, M., Marelli, L., Manzoni, M., Araneo, L., Filippeschi, A., \& Marengo, M. (2014). Closed loop pulsating heat pipe: ground and microgravity experiments, Proc. Of the 9th International Conference on two-phase systems for ground and space applications.

[11] Mangini, D., Mameli, M., Georgoulas, A., Araneo, L., Filippeschi, S., \& Marengo, M. (2015). A pulsating heat pipe for space applications: ground and microgravity experiments. Int. Journal of Thermal Science, 95, 55-63.

[12] Zhang, Y., \& Faghri, A. (2008). Advances and unsulved issues in pulsating heat pipes. Heat Transfer Engineering, 29, 20-44.

[13] Tang, X., Sha, L., Zhang, H., \& Ju, Y. (2013). A review of recent experimental investigations and 
theoretical analyses for pulsating heat pipes. Front. Energy, 7, 161-173.

[14] Miyazaki, Y., Akachi, H., Polasek, F., \& Stulk, P. (1996). Heat transfer characteristics of looped capillary heat pipe. Proc. of the 5th Int. Heat Pipe Symposium.

[15] Miyazaki, Y., \& Akachi H. (1998). Self excited oscillation of slug flow in a micro channel. Proc. of the 3rd Int. Conf. on Multiphase Flow.

[16] Zuo, Z.J., North, M.T., \& Ray, L. (1999). Combined pulsating and capillary heat pipe mechanism for cooling of high heat flux electronics, Proc. ASME Heat Transfer Device Conference.

[17] Zuo, Z.J., North, M.T., \& Wert, K.L. (2001). High heat flux heat pipes for cooling of electronics. IEEE Transactions on Components and Packaging Technologies, 24-2, 220-225.

[18] Wong, T.N., Tong, B.Y., Lim, S.M., \& Ooi, K.T. (1999). Theoretical modeling of pulsating heat pipe. Proc. 11th International Heat Pipe Conference.

[19] Das, S., Nikolayev, V., Lefèvre, F., Pottier, B., Khandekar, S., \& Bonjour, J. (2010). Thermally induced two-phase oscillating flow inside a capillary tube. Int. J. Heat Mass Transfer, 53, 3905-3913.

[20] Nikolayev, V.S., (2011). A dynamic film model of the pulsating heat pipe, J. Heat Transfer, 133-8.

[21] Holley, B., \& Faghri, A., (2005). Analysis of pulsating heat pipes with capillary wick and varying channel diameter. Int. J. Heat Mass Transfer, 48, 2635-2651.

[22] Mameli, M., Marengo, M., \& Zinna, S. (2012). Thermal simulation of a pulsating heat pipe: effects of different liquid properties on a simple geometry. Heat Transfer Engineering, 33, 1177-1187.

[23] Mameli, M., Marengo, M., \& Zinna S. (2012). Numerical model of a multi-turn closed loop pulsating heat pipe: effect of the local pressure losses due to meanderings. Int. J. Heat Mass Transfer, 55, 10361047.

[24] Mameli, M., Marengo M., \& Zinna, S. (2012). Numerical investigation of the effects of orientation and gravity in a closed loop pulsating heat pipe. Microgravity Science and Technology, 24-2, 79-92.

[25] Khandekar, S., Cui, X., \& Groll, M. (2002). Thermal performance modeling of pulsating heat pipe by artificial neural networks, Proc. of 12th Int. Heat Pipe Conf.

[26] Chen, P.H., Lee, Y.W., \& Chang, T.L. (2009). Predicting thermal instability in a closed loop pulsating heat pipe system, Appl. Therm. Eng., 29-8, 1566-1576.

[27] Lee, Y.W., \& Chang, T.L. (2009). Application of NARX neural networks in thermal dynamics identification. Energy Convers. Manage, 50-4, 1069-1078.

[28] Liu, X.D., \& Hao, Y.L. (2009). Numerical simulation of vapor-liquid two-phase flow in a closed loop oscillating heat pipe. Proc. of the ASME 2009 Int. Mechanical Engineering Congress and Exposition.

[29] Lin, Z., Wang, S., Shirakashi, R., \& Zhang, L.W. (2013). Simulation of a miniature oscillating heat pipe in bottom heating mode using CFD with unsteady modeling. Int. Journal of Heat and Mass Transfer, 57, 642-656.

[30] Manzoni, M., Mameli, M., de Falco, C., Araneo, L., Filippeschi, S., Marengo, M. (2016). Advanced numerical method for a thermally induced slug flow: application to a capillary Closed Loop Pulsating Heat Pipe. International Journal of Numerical Methods in Fluids. ACCEPTED FOR PUBLICATION.

[31] Hairer, E., \& Wanner, G. (1996). Solving Ordinary Differential Equations II. Stiff and DifferentialAlgebraic Problems. Springer.

[32] Hairer, E., Lubich, C., \& Wanner, G. (2003). Geometic numerical integration illustrated by the StörmerVerlet method. Acta Numerica, 12, 399-450

[33] Incropera, F. P., \& DeWitt, D. P. (2007). Chapter 8: internal flow. Fundamentals of Heat and Mass Transfer, 6th Ed.

[34] Haaland, S. (1983). Simple and explicit formulas for the friction factor in turbulent flow. Transactions of ASME, Journal of Fluids Engineering, 103, 89-90.

[35] Darby, R. (2001). Correlate pressure drop through fittings. Chemical Engineering, 104,127-130.

[36] Shah, R. K., \& London, A. L. (1978). Laminar flow forced convection in ducts. Advanced in Heat Transfer.

[37] Shafii, M.B., Faghri, A., \& Zhang, Y. (2001). Thermal modeling of unlooped and looped pulasating heat pipes. Journal of Heat Transfer, 123, 1159-1172.

[38] Baldassari, C., \& Marengo, M. (2013). Flow boiling in microchannels and microgravity. Progress in Energy and Combustion Science, 39-1, 1-36.

[39] Harichian, T., \& Garimella, S. (2010). A comprehensiveflow regime map for microchannel flow boiling with quantitative transition criteria. Int. Journal of Heat and Mass Transfer, 53, 694-702. 